\title{
Marx no era \\ marxista-leninista
}

RicARDO RIBERA

Departamento de Filosofía Universidad Centroamericana "José Simeón Cañas" 
En estas Jornadas "Ignacio Ellacuría", dedicadas este año a Marx y el pensamiento crítico, bueno será tomar en cuenta la recomendación del propio Ellacuría de fijar la atención en el momento y en el lugar de la reflexión. En este sentido, permítanme leer la noticia de este día sobre el comienzo del Foro Económico Mundial, más conocido como el Foro de Davos. Según la nota de la agencia EFE, la reunión es "para dar una nueva forma a un mundo que está sumido en varias crisis, que hacen necesaria una redefinición del capitalismo". En otra noticia, El Diario de $\mathrm{Hoy}^{3}$ recoge la posición del papa Francisco: "No se puede tolerar que millones de personas mueran cada día de hambre, máxime cuando existen cantidades ingentes de comida que, a menudo, son sencillamente desperdiciadas". El Sumo Pontífice agrega: "Tampoco nos pueden resultar indiferentes los numerosos migrantes que van hacia la muerte en viajes inhumanos". Huelga decir que ni el citado periódico ni el jerarca de la Iglesia católica son sospechosos de tener influencias marxistas. No obstante, la inquietud que aquí reflejan sí es común con la de Marx.

Tampoco podemos dejar pasar por alto la fecha del día de hoy, 22 de enero, aniversario importante para la historia del pueblo salvadoreño. Su evolución sigue marcada por otro 22 de enero, el de 1932, cuando el levantamiento popular, campesino, indígena, convocado y organizado por el Partido Comunista, escribió una página de lucha en el libro de la historia, que transformó para siempre a la nación. La intentona insurreccional duró unos pocos días, pero la represión se prolongó varios meses, convirtiéndose en el primer genocidio del país desde su independencia. Roque Dalton resumió poéticamente el impacto de la masacre: "Todos nacimos medio muertos después del $32 "$.

Asimismo, hay que señalar otra gesta histórica: la mayor manifestación política de masas de la historia del país, la que encabezó la Coordinadora Revolucionaria de Masas, CRM, que fue embrión del Frente Democrático Revolucionario, FDR, y que era resultado de la inicial confluencia de las organizaciones revolucionarias de la época, un proceso de unificación de la izquierda marxista que culminaría con la fundación del Frente Farabundo Martí para la Liberación Nacional, FMLN. Aquella marcha del 22 de enero de 1980 se asomó al borde del inminente conflicto armado; movilizó a unas trescientas mil personas que pacíficamente salieron a las calles pese al riesgo de ser reprimidas y masacradas, como de hecho ocurrió.

Hace escasos seis días celebramos otro aniversario de la firma del Acuerdo de Paz, que tras doce duros años de guerra civil signi- 
ficó la salida político-negociada al conflicto, que ha supuesto la superación de más de medio siglo de dictadura y terrorismo de Estado.

Esas son indispensables referencias para ubicar la oportunidad de la temática que hoy nos reúne acá, en este espacio de la Academia. Nuestro presente actual de transformaciones y cambios en democracia no se habría alcanzado sin escalar esos peldaños históricos, en el diferido ascenso del pueblo hacia el puesto de mando, ahí donde se toman las decisiones que pueden definir su futuro y su destino.

Contrastante con las efemérides mencionadas es el momento por el que hoy atravesamos: a escasos once días de las elecciones presidenciales, tras una larga y -hay que decirlo- poco motivadora campaña electoral. Está en juego la posibilidad de un segundo gobierno de la izquierda que pueda profundizar los cambios iniciados el 2009 o, de no darse, el retroceso a otro período de neoliberalismo y autoritarismo conservador, caso de que regrese la derecha al control del poder ejecutivo. La importancia de la coyuntura pareciera absorber energías y atención ciudadanas en una medida desmesurada, con el riesgo de que se pierda de vista la amplitud y los alcances del proceso histórico en su conjunto.

Resulta un buen momento para, desde la Academia, poner la atención en cosas de estrategia y un poco menos en las cuestiones tácticas, para revisar el largo plazo y ya no solo el corto plazo. Para decirlo de otra manera: tenemos la mirada puesta en los pies, para no tropezar, y el llamado es a levantar los ojos, para mirar hacia delante y ver para dónde vamos. Aquí voy a intentar aportar en tal sentido con esta breve ponencia, cuyo título puede parecer una tontería, una bayuncada, pero que sirve de provocación: Marx no era marxistaleninista.

Por un lado, es evidente que Marx no era leninista, que no podía serlo; pero, por otro lado, el título provoca a la reflexión sobre las diferencias entre el marxismo de Marx $y$ el de Lenin. Es obvio que Lenin fue marxista, pero ¿qué tipo de marxismo era el suyo? Ha habido y hay varios marxismos. Ha habido y hay diferentes lecturas de la obra de Marx. ¿Cuáles son de más interés a la altura de nuestra época? ¿Qué de Marx vuelve a ser actual? ¿En qué cosas Lenin nos sigue interesando y en cuáles ya no?

Por otro lado, ¿es marxismo ese que se presenta cientificista, académico, no comprometido con las luchas políticas y con la aspiración a la revolución y al socialismo? $\mathrm{O}$, dicho de otra manera, ¿se puede ser marxista sin ser revolucionario? Y la pregunta indispensable, al menos en El Salvador: ¿se puede ser revolucionario sin ser leninista? 
Son ya suficientes interrogantes, aunque mejor completemos la lista con otras igual de imprescindibles: ¿cómo tomar el poder? O, si no se puede tomar, ¿cómo llegar al poder? Una vez ahí, ¿qué hacer con él? Y asimismo: ¿cómo pensamos el socialismo?, ¿qué modelo nos inspira? ¿Es solo un modo de producción diferente o de lo que se trata es de vivir de otra manera? ${ }^{4}$

Aunque resulta evidente que la tarea revolucionaria consiste en "pensar lo nuevo", que "el futuro hay que inventarlo" y que se requiere "pensar con cabeza propia", nunca se parte de cero ni estamos desarmados teóricamente ante los presentes desafíos. La historia nos ofrece todo un bagaje de experiencias prácticas y de elaboraciones teóricas que habrá que asimilar y reelaborar. En este sentido, es preciso un diálogo entre nuestra época y el siglo XX, a fin de recuperar toda la riqueza de conocimiento que, no solo las revoluciones victoriosas, sino también algunas de las experiencias derrotadas o fracasadas nos brindan, si sabemos releer sus renglones. No solo hay que poner a dialogar ambas centurias. También del siglo XIX Ilegan mensajes que nos interpelan, ciertos pasajes cobran hoy más relieve del que tuvieron en el siglo pasado. De ahí la actualidad de Marx y la de Lenin, a los que nos ceñiremos acá, aun sabiendo que no se agota en ellos la temática.

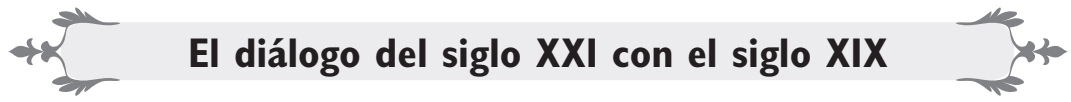

Hay una serie de aspectos de la obra de Marx que seguramente son más comprensibles hoy, al leerlas en el siglo actual, que en la época en que fueron escritos por su autor. Tal es el poder de anticipación de Marx. Es así en cuestiones relativas al desarrollo de la técnica y de las fuerzas productivas en general, pero también en aspectos críticos como la alienación (en el consumismo ${ }^{5}$ por ejemplo) o la inadecuada relación hombre/ naturaleza, que en el sistema capitalista lejos de ser armoniosa pasa a adoptar el sello que le es propio de explotación y dominio, con el consiguiente agotamiento de recursos y el socavamiento de las condiciones de supervivencia de la especie humana. Más claramente hoy, en nuestra centuria, que en el siglo XIX, la dialéctica invierte dramáticamente los términos $y$, tal como predijo Marx, las fuerzas productivas se convierten en fuerzas destructivas. Por eso, podemos afirmar que no es solo que nuestra época permite entender mejor a Marx, es válido también el aserto contrario: el estudio de la obra de Marx permite comprender mejor las contradicciones y la problemática de nuestros tiempos. 
Pero así como para captar a cabalidad la obra de Lenin es imprescindible el estudio previo de Marx, lo mismo puede decirse de este con respecto a Hegel. Sin un cierto conocimiento de su obra filosófica, difícilmente se van a entender las formulaciones de Marx, su implícito diálogo con el sistema hegeliano, su utilización de la dialéctica como método de análisis.

De otra parte, al igual que el tiempo le ha dado la razón a ciertas tesis marxistas con mayor rotundidad que cuando fueron formuladas, algo similar ocurre con Hegel. El propio Marx, a pesar de haber iniciado su recorrido teórico confrontando, rebatiendo y superando la obra de Hegel, lo culmina reencontrándose con la misma y recuperando aspectos que a la hora de redactar El capital le son útiles y a los que reconoce su validez.

Ellacuría, quien pese a no ser marxista conocía muy a fondo la obra de Marx, dejó explícito el siguiente apunte: "El 16 de enero de 1858, cuando Marx andaba escribiendo ya su cuarto cuaderno de notas [de los Grundrisse o Elementos fundamentales para la crítica de la economía política] escribía a Engels que en su método de trabajo le había sido de gran utilidad el haberse encontrado accidentalmente de nuevo con la Lógica de Hegel. Por algo advertía Lenin que es completamente imposible entender El capital de Marx sin haber estudiado completa la Lógica de Hegel. Lo cual no se comprendería si tanto los Grundrisse como El capital no hubieran tomado de Hegel más que unas vacías formulaciones metodológicas". ${ }^{6}$

El carácter humanizador y creativo del trabajo, el concepto de "alienación" o "enajenación", e incluso muchos aspectos de la crítica a la sociedad burguesa los obtuvo Marx de Hegel. ${ }^{7}$ Es notable el caso de la dialéctica entre el amo y el esclavo (Fenomenología del Espíritu), muy influyente en la obra marxiana. Por otra parte, hay aspectos de la obra de Hegel donde nuestra época le ha dado la razón, matizando o neutralizando la crítica de Marx.

Hegel fue el primero en resaltar la importancia que alcanzaría con el tiempo la clase media dentro de la sociedad burguesa y su capacidad mediatizadora. Esto, no solo no lo aceptaba Marx, sino que viene a contradecir en parte su tesis de la tendencia a la polarización de la sociedad moderna en dos clases contrapuestas, burguesía y proletariado. Ciertamente hay proletarización de una serie de profesiones u oficios que antes fueron ejercidos por los artesanos o eran el dominio de las llamadas profesiones liberales (médicos, abogados, etc.); sin embargo, qué duda cabe que el desarrollo y creciente papel de las capas medias marcan el mundo contemporáneo de tintes descono- 
cidos en la paleta con que pintaba Marx a la sociedad moderna. Lejos de simplificarse, las contradicciones de clase tienden a volverse más complejas en la llamada sociedad post-industrial.

Algo parecido puede decirse de la tesis marxiana sobre la creciente pauperización de los trabajadores. Es verdadera en ciertos aspectos del mundo globalizado, en especial en las sociedades del Ilamado Tercer Mundo, como señalábamos anteriormente cuando citábamos al papa Francisco; pero, por otra parte, resulta falseada por la amplitud de la "aristocracia obrera" o la pujanza del sector terciario de servicios, con sus empleados "de cuello blanco" y sus empleadas con maquillaje y zapatos de tacón. Es decir, la visión de Hegel del futuro resulta, en algunos aspectos, más cercana a una descripción de la realidad del mundo actual que la de Marx, muy anclada en las duras etapas de la acumulación primitiva de capital.

Hegel también acierta en la predicción sobre el advenimiento de una "clase política" ligada al aparato del Estado, así como la inevitable y perniciosa "burocratización" del mismo, que entraría en contradicción con su esencia. Marx le reprocha a Hegel presentar como ideal al Estado real, haber idealizado al Estado burgués. Lo ha mostrado como culminación de la evolución humana, como máxima realización del espíritu, como esce- nario de las máximas posibilidades de la libertad. La crítica de Marx es precisa y contundente.

Marx tiene razón al reclamar que el Estado es siempre Estado de clase, que es neutral solo en apariencia, que siempre está al servicio de la clase dominante y que en eso consiste su esencia. No obstante, convendrá retomar la dialéctica entre esencia y apariencia, a fin de no menospreciar la importancia de esta última. El propio Hegel la desarrolló: la esencia niega a la apariencia. Resulta ser su opuesto. Las cosas no son como parecen, sino que más bien son todo lo contrario. No obstante, la apariencia es un momento indispensable: todo lo que es, aparece, y todo lo que aparece lo hace bajo la forma de apariencia.

En el caso que nos ocupa: el Estado, siendo como es Estado de clase, no puede dejar de presentarse como neutral y de "aparentar" estar al servicio de las distintas clases por igual. La falsedad última de la apariencia no la priva de su necesariedad ni hace que desaparezca o se disuelva en la esencia. La lucha política en el marco de las democracias burguesas juega justamente con esta ambigüedad. Si hay espacio para el juego político precisamente es porque no todo se resuelve en lo que las cosas son "en su esencia", en este caso, en el carácter clasista del Estado. La crítica de Marx, aun siendo verda- 
dera, no agota de hecho las posibilidades de lo real, ni supone toda la verdad de la realidad. Es más que una sutileza.

Volviendo sobre lo mismo desde otro ángulo: Marx ha planteado el carácter ilusorio de las luchas que se dan en el Estado y por el Estado. Es su forma de refutar a Hegel e invertir los términos. No es en el Estado, sino en la sociedad donde se juega el destino de los pueblos. Es la sociedad el escenario principal de la historia. Es la lucha de clases el motor principal de la misma, y ella se verifica en la sociedad. ${ }^{8}$ Califica por tanto de ilusorias, de irreales, las luchas en el marco del Estado, las de los partidos, las que protagonizan los políticos. Marx sienta con ello las bases para una concepción o filosofía de la historia, pero no propiamente la dota de herramientas para el análisis histórico o para la construcción de la historia como ciencia. Lo mismo ocurre con su tesis de que "son las masas las que hacen la historia", en refutación a Bruno Bauer, hegeliano de izquierda, quien había enfatizado exageradamente el papel del protagonismo individual. O sea, aun aceptando las tesis del materialismo histórico de Marx y su teoría de la lucha de clases, habrá que emprender el análisis teórico y la praxis política de las luchas concretas en el Estado y por el Estado, a despecho de los calificativos de "irreales" o "ilusorias". La praxis histórica de los partidos marxistas lo confirma.
Por ahí se abre un flanco que el marxismo de Marx ha cubierto insuficientemente: el de la conceptualización del Estado de Derecho. Es un tema de mucha actualidad, a la vista de las experiencias del Ilamado "Socialismo del siglo XXI". Sobre el mismo hallaremos muchos más elementos teóricos en Hegel, pues para el filósofo prusiano se trata de un estadio de la historia, de los más elevados en la evolución del espíritu, de la racionalidad y la libertad humanas. En la medida que nuestra centuria valora en mayor medida la democracia y los derechos humanos, planteándose el socialismo como su ulterior desarrollo y expansión, y no como algo a superar a nombre de no importa cuál dictadura, en dicha medida resulta de interés el aporte de Hegel. En especial, por darse su planteamiento fuera del marco teórico del liberalismo. Igual que la democracia es anterior al capitalismo y no es un "producto" de ese modo de producción, la racionalidad propia del derecho constitucional y las normas que rigen el moderno Estado de Derecho desbordan el mundo de la burguesía.

Todo lo que es, aparece, y todo lo que aparece, desaparece. Es la concepción sintetizada de Hegel, por la cual todo está en devenir, todo es proceso. También el Estado está Ilamado a desaparecer. Pero Hegel pareciera olvidar aplicar su propia receta al tema del Estado. En esto Marx le corrige la plana. La 
verdadera libertad y la humanización plena se alcanzarán sobre las ruinas del Estado, negándolo, haciéndolo desaparecer. La realización de la historia como concreción de la libertad -tal como la concibió Hegel- debe interpretarse más bien como la historia de la liberación. Se trata de liberación y no solo de libertad. Liberación de todo lo que oprime y sojuzga al ser humano. Liberación, por tanto, del Estado. Para Marx, el comunismo será la "sociedad autorregulada". No solo liberación "de", también liberación "para". Liberación para hacer posible la vida plenamente humana.
Es un planteamiento que lo aproxima mucho al ideal anarquista, con una diferencia que para Marx es sustancial: el camino para llegar a tal meta es diferente y, con ello, la propia meta cambia. Para poder destruir el Estado, para poder "extinguirlo", hace falta primero su conquista e incluso su expansión. Solo desde la dialéctica cobra sentido la apuesta de Marx: la dictadura del proletariado, el Estado proletario, supone el tránsito para eliminar el Estado y alcanzar el comunismo, pero dicha transición pasa por su reforzamiento temporal.

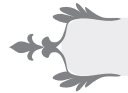

El diálogo del siglo $X X I$ con el siglo $X X$
Engels sintetiza en su obra AntiDühring estas ideas al respecto: "El proletariado toma el poder estatal y comienza por convertir los medios de producción en propiedad del Estado. Pero con este acto se destruye a sí mismo como proletariado y destruye toda diferencia y todo antagonismo de clases y, con ello mismo, el Estado como tal". Lenin, en El Estado y la revolución, lo reafirma: "Nosotros nos proponemos como meta final la destrucción del Estado, es decir, de toda violencia organizada y sistemática". Pero, compelido a resolver en la práctica, por primera vez en la historia, los problemas tras la toma del poder por la clase obrera, está claro que se trata de un proceso largo: "Es probable que ni siquiera la próxima generación, más evolucionada, logre completar su transición al socialismo". Un año más tarde, en 1919, insistía: "Sabemos que al presente no podemos implantar el orden socialista y nos daríamos por satisfechos con que lo pusieran en práctica nuestros hijos y tal vez nuestros nietos". ${ }^{\prime}$

Lenin impulsó primero el "comunismo de guerra", que estatizó las empresas y creó la figura de los comisarios políticos (de partido) para enfrentar la necesidad de ganar la guerra civil. Pero una vez resuelta esta, concibió la NEP (Nueva Política Económica) que establecía una suerte de economía mixta. Buscaba con ello fortalecer la alianza obrero-campesina, innovación teórica y práctica con respecto 
lo previsto por Marx, indispensable a su criterio en un país básicamente agrario como era Rusia.

Lenin había estudiado a fondo la economía y estructura de clases de su país. Lo hizo antes incluso de haber sido fundado el partido, aprovechando su encarcelamiento en diciembre de 1895. Dedicó los tres años de encierro a la preparación de El desarrollo del capitalismo en Rusia, libro que publicó en 1899. Está dedicado a "examinar la siguiente cuestión: ¿cómo se forma el mercado interior para el capitalismo ruso?"10 Estudia en tres capítulos cómo se ha desarrollado la industria capitalista en el país. Antes ha dedicado otros tres a examinar la desintegración del campesinado, la transición de la economía terrateniente de tipo feudal a la forma capitalista y, por último, las modalidades de la agricultura mercantil y capitalista.

A la altura de 1908, cuando redacta el Prefacio para la segunda edición de la obra, tiene totalmente claras las consecuencias políticas que se derivan de su investigación: "Partiendo de esta base económica, se comprende que la revolución en Rusia es, inevitablemente, una revolución burguesa. Esta tesis marxista es absolutamente irrefutable. No se la debe olvidar jamás. Siempre hay que aplicarla al análisis de todas las cuestiones económicas y políticas de la revolución rusa".$^{11}$ Está claro, por tanto, que las diferencias de los bolcheviques, que él encabeza, con los mencheviques no residen en su definición del carácter de la revolución que está pendiente en Rusia. Así fue hasta 1917, el año de la doble revolución rusa.

La decisión de no detenerse en el estadio burgués de la revolución, alcanzado en febrero, la tomó Lenin justo al regreso de su exilio en Suiza, y sus argumentos aparecen en las Tesis de abril. Muchos camaradas quedaron atónitos. Su Ilamado a derrocar el gobierno provisional surgido de la revolución que había derribado al zar, a entregar todo el poder a los soviets y saltar a la revolución socialista, iba contra la línea del partido y de lo que había sostenido hasta entonces el propio Lenin. El filósofo Zizek recoge algunas reacciones: Bogdanov caracterizó las Tesis de abril como "el delirio de un loco", y la propia Krupskaya concluyó: "Tengo miedo, parece como si Lenin hubiera perdido la razón"..12

Sin embargo, el propio Zizek analiza y justifica la postura leninista: "La lección fundamental del materialismo revolucionario es que la revolución debe golpear dos veces". Lo que falta a la primera revolución no es el contenido, sino su forma misma: la idea de que la libertad y la justicia pueden lograrse haciendo funcionar el aparato estatal existente y sus mecanismos democráticos. Es "la negación de la negación hegeliana: primero el viejo orden es negado dentro de su 
propia forma ideológico-política; luego esta forma tiene que ser negada. Los que vacilan, que temen dar el segundo paso de superar la forma misma, son los que quieren una 'revolución sin revolución". ${ }^{13}$

Ya en 1905, al calor de las luchas revolucionarias, Lenin había adelantado algo de la doble revolución pendiente en las condiciones rusas: "El proletariado debe llevar a término la revolución democrática atrayéndose a la masa de los campesinos para aplastar por la fuerza la resistencia de la autocracia [dictadura zarista] y paralizar la inestabilidad de la burguesía; el proletariado debe llevar a cabo la revolución socialista atrayéndose la masa de elementos semi-proletarios para destrozar por la fuerza la resistencia de la burguesía y paralizar la inestabilidad de los campesinos y de la pequeña burguesía". ${ }^{14}$ Lo que no se planteaba en tal momento es que fueran consecutivas, similar a la 'revolución permanente' de Trotsky.

Por otra parte, no puede obviarse la tragedia de la deformación estalinista y de sus crímenes: "La constelación única de acontecimientos que posibilitó la toma revolucionaria del poder en octubre no puede separarse de su posterior giro 'estalinista. La famosa alternativa de Rosa Luxemburg ('socialismo o barbarie') terminó (...) afirmando la identidad especulativa de las dos condiciones opuestas: el socia- lismo realmente existente fue la barbarie".$^{15}$ Es el juicio, después de la caída del muro de Berlín y del desplome de la Unión Soviética, tal vez demasiado severo, dadas las dificultades excepcionales que los bolcheviques enfrentaron.

Manuel Sacristán ${ }^{16}$ examinó, de una manera más ponderada, las relaciones entre leninismo y estalinismo y expuso sus diferencias esenciales. Con Stalin sobrevino la concentración de poder, hasta convertirse en dictadura personal; la represión se convirtió en terror. Apoyó al nacionalismo ruso. Repugna su cinismo ideológico. "Stalin canonizó como justo y acertado lo que no era más que el estado de necesidad: hambre, escasez, represión. Construyó teoría para justificar la práctica, retorció y deformó conceptos. Como la idea del socialismo en un solo país o la de social-fascismo. La gran diferencia: su pragmatismo ideológico".

A partir del triunfo de la Revolución rusa, muchos aspectos que en el siglo XIX estaban solo perfilados debieron desarrollarse $y$ concretarse. El leninismo surge en otra época histórica que requiere de ideas nuevas; "el marxismo es algo vivo que se desarrolla y modifica" ${ }^{17}$ "El leninismo es el marxismo de la época del imperialismo"; no es solo su aplicación a las condiciones concretas de Rusia, sino que "es un desarrollo del marxismo" ${ }^{18}$ 
Lo que caracterizaba al antiguo capitalismo donde reinaba la libre concurrencia, era la exportación de mercancías; lo que caracteriza al actual, donde reinan los monopolios, es la exportación de capitales". ${ }^{19}$ "La libre competencia es la característica fundamental del capitalismo y de la producción mercantil en general; el monopolio es todo lo contrario de la libre competencia; pero esta última se va convirtiendo ante nuestros ojos en monopolio, creando la gran producción (...) el imperialismo es la fase monopolista del capitalismo. ${ }^{20}$

Las posibilidades del triunfo de una revolución socialista en Rusia las sitúa Lenin en el marco de la era del imperialismo: Rusia sería "el eslabón más débil de la cadena de países imperialistas". Pero, por ello mismo, por el atraso que caracteriza a su sociedad y al Estado zarista, las condiciones para la lucha política del proletariado presentan la gran dificultad de enfrentar un régimen despótico y muy represivo. De ahí que Lenin desarrolle uno de los aspectos que resultan más originales y a la vez más heterodoxos de su obra: su concepción o teoría del partido.

Está expuesta básicamente en el ¿Qué hacer? Problemas candentes de nuestro movimiento, libro editado en marzo de 1902, que desarrolla las ideas de un artículo anterior "¿Por dónde empezar?", publicado en Iskra, en mayo de 1901. Expone un planteamiento novedoso que parte de su crítica al economicismo.

La lucha política de la socialdemocracia ${ }^{21}$ es mucho más amplia y compleja que la lucha económica de los obreros contra los patronos y el gobierno. Del mismo modo, la organización de un partido revolucionario debe ser inevitablemente de un género distinto que la organización de los obreros para la lucha económica. La organización de los obreros debe ser sindical, lo más extensa posible, lo menos clandestina posible. La organización de los revolucionarios, al contrario, debe englobar ante todo y sobre todo a gentes cuya profesión sea la actividad revolucionaria. Esta organización, necesariamente, no debe ser muy extensa, que sea lo más clandestina posible. ${ }^{22}$

Para Marx estaba muy claro que el proletariado desarrolla su conciencia de clase. Es la conse- cuencia de la idea de que "no es la conciencia de los hombres la que determina su ser; por el contrario, 
su ser social es lo que determina su conciencia". ${ }^{23}$ El proletariado, por serlo, es revolucionario. Pero la teoría del partido que expone Lenin da un giro completo a lo planteado por Marx: "La emancipación de los trabajadores no es ya obra de los propios trabajadores, sino del instrumento que les representa y dirige. El partido no es la clase organizada en y por la lucha de clases, sino el medio de esa lucha. La dialéctica de la clase transformando la sociedad se convierte ahora en una relación entre el partido de vanguardia y la clase que este representa".$^{24}$

Para Lenin, los obreros tienden a caer en el tradeunionismo y el economicismo. Coincide con Kautsky y lo cita en el ¿Qué hacer?: "La conciencia socialista es algo introducido desde fuera en la lucha de clases del proletariado y no algo que ha surgido espontáneamente dentro de ella". Pero mientras el socialdemócrata alemán lo argumenta por el papel que la ciencia y la técnica, nacidas en la intelectualidad burguesa, juegan para el surgimiento de la conciencia socialista, Lenin lo asume por las condiciones concretas existentes en Rusia, y desechará tales concepciones cuando las condiciones cambien, por ejemplo en coyunturas de auge revolucionario como las de 1905 y 1917. Él mismo es consciente de la exageración de su postura cuando explica: "Los economicistas torcieron el bastón hacia un lado; para enderezarlo había que torcerlo al lado opuesto y eso es lo que yo he hecho". ${ }^{25}$

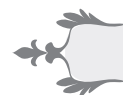

\section{Lenin en El Salvador}

El triunfo de la revolución en Rusia enfatizó el papel protagónico de los bolcheviques y en especial del genio político de Lenin. Pero, además, su concepción de partido de cuadros, de militantes, de revolucionarios profesionales, encajó con las condiciones predominantes en los países del Tercer Mundo, donde a falta de condiciones objetivas sobraban condiciones subjetivas para intentar la revolución. El 'centralismo democrático' de Lenin, en el que resultaba enfatizado el sustantivo "centralismo" y no tanto el adjetivo "democrático", moldeó organizaciones creadas para preparar la revolución en condiciones de dictadura y de represión. $Y$ mostró su eficacia y su idoneidad en muchos lugares. Mientras en países de capitalismo desarrollado el aburguesamiento y las tendencias reformistas predominaban, en los países dependientes y subdesarrollados proliferaron organizaciones revolucionarias que se identificaban con el marxismo-leninismo. Al punto que este pasó a ser sinónimo de "izquierda revolucionaria", mientras que el calificativo de "izquierda democrática" quedó para los partidos declaradamente reformistas y revisionistas. 
Escribía Lenin en el ¿Qué hacer?: "Las organizaciones obreras para la lucha económica deben ser organizaciones sindicales (...) que participe en la unión gremial todo obrero que comprenda la necesidad de la unión para la lucha contra los patronos y contra el gobierno (...) Y cuanto más amplias sean estas organizaciones, tanto más amplia será nuestra influencia en ellas (...). Pero, en una organización amplia, la clandestinidad rigurosa es imposible. ¿Cómo conciliar esta contradicción entre la necesidad de contar con efectivos numerosos y el régimen clandestino riguroso?"26 Pues bien, esta interrogante práctica hecha por Lenin se resolvió de una manera creativa en El Salvador en los años setenta. El movimiento popular se estructuró en los llamados frentes de masas (BPR, FAPU, etc.), los cuales estaban articulados con las organizaciones revolucionarias. La difícil combinación entre un amplio trabajo político de masas y la labor conspirativa de una vanguardia revolucionaria, a la que hacía referencia el dirigente bolchevique, se logró en El Salvador de manera muy efectiva.

Es en dicha capacidad donde se evidencia con más claridad que la izquierda revolucionaria salvadoreña, que abrazó la lucha armada desde 1970, se organizó siguiendo lineamientos leninistas. La masividad del movimiento popular orientado por dichas organizaciones llegó a sobrepasar, a fines de la década, las movilizaciones en torno a la lucha electoral, que entre 1972 y 1977 impulsó la Unión Nacional Opositora, UNO. Pasar del simple hostigamiento guerrillero a una confrontación armada suficientemente potente como para tomar el carácter de una verdadera guerra civil, sin esa base popular organizada no hubiera sido posible.

La guerra tampoco era posible sin un proceso de unidad para una mínima coordinación y garantizar que las rivalidades entre las diferentes organizaciones revolucionarias no fueran a degenerar en choques armados. Debía construirse un ejército revolucionario unificado, único, o se corría el riesgo de luchas fratricidas. Eso ocurría en Colombia y era el ejemplo de lo que debía evitarse. De ahí la necesidad de dotarse de un programa común y de aspirar a unificarse en un solo partido de vanguardia, a fusionar estructuras como FMLN.

Ante esta necesidad perentoria, el leninismo mostró entonces sus limitaciones, por lo menos el tipo de lectura dogmática, estalinista, que se tenía del leninismo. Posiblemente el propio Lenin no hubiera incurrido en el esquematismo fatal, pues era muy consciente de interpretar el marxismo como un medio de orientación y no como un dogma cerrado. "Innumerables errores tienen como origen el hecho de que las consignas y las medidas a adoptar, justas en un momento dado 
y en una determinada situación, son mecánicamente aplicadas en una situación histórica, una relación de fuerzas y un estado de cosas diferentes". ${ }^{27} \mathrm{El}$ problema es que no fue el leninismo de Lenin, sino más bien el de Stalin el que se propaló por todas partes, incluido El Salvador. Un leninismo fosilizado, esquemático, mecánico, dogmático y, lo peor, que podía llegar a extremos brutales. En el transcurso de la guerra, esa variedad de leninismo no estuvo a la altura de la época, para decirlo en forma suave, y más bien mostró que en su deformación podía caer en lo criminal.

Para expresar mi tesis de forma concreta y provocativa: Marcial fue el último leninista de El Salvador. Decir eso me obliga, por un lado, a demostrar que Salvador Cayetano Carpio, Marcial, era efectivamente leninista. Por otro lado, a mostrar cómo ese leninismo, aplicado de manera mecánica y dogmática, no encajaba en las condiciones cambiantes del proceso revolucionario salvadoreño. Más bien condujo al fundador de las FPL a deformaciones y concepciones erradas, hasta incurrir en la conducta criminal que en abril de 1983 llevó al asesinato de la comandante Ana María (Mélida Anaya Montes) y a su propia muerte, en condiciones que deshonraron su legado histórico y político.

Las posturas de Marcial en diferentes temas son ortodoxamente leninistas. Así, a la altura de mediados de 1982, en los cuadernos reunidos bajo el título El Partido Marxista Leninista del Proletariado, aborda la necesidad de que el proletariado se dote de su propio partido, lo cual es diferente a la ideología difusa o pequeñoburguesa del FMLN. Las FPL serían el germen de dicho partido de clase, partido marxista leninista, verdadera vanguardia por lo tanto del pueblo salvadoreño.

Se forma un frente cuando hay distintas organizaciones que necesitan unirse y aliarse en determinada plataforma de lucha; pero es frente precisamente porque todavía no puede convertirse en partido. El partido necesita centralización (...) un solo enfoque (...) una sola ideología (...). El FMLN no es eso y no puede serlo en mucho tiempo. Hay diversas ideologías, incluso que chocan entre sí.

Más adelante concluye:

Por eso la marcha hacia la construcción de un partido único, a través del FMLN, es sumamente compleja. Si nosotros consideráramos que no debemos organizar el partido del proletariado a partir del las FPL, porque ya hay un FMLN, 
nosotros estamos cayendo en el más grave error y las más grave interpretación de lo que debe ser la lucha de clases para hacer avanzar los intereses del proletariado. Esa meta errónea nos la trazamos en 1980. Por suerte vimos que era idealista, utópica, infantil. ${ }^{28}$

Para Marcial, la vanguardia no es el FMLN, sino que han de ser las FPL; por eso, el concepto de ser el núcleo marxista leninista dentro del Frente, de vanguardia dentro de la vanguardia. Era una concepción sectaria y hegemónica que atentaba contra la unidad, no solo entorpecía el proceso de unificación, sino que ponía en peligro el mantenimiento mismo del FMLN.
La intención de Marcial era promover un acercamiento entre las FPL y el PCS para formar un núcleo marxista en el seno del FMLN, siendo que el resto de organizaciones del Frente serían simples aliados temporales, por no ser confiables y tener otras ideologías:

Les dijimos que entre las FPL y el PCS existe un tronco común, que es la teoría del marxismo leninismo (...). Las discrepancias fueron en cómo interpretar y aplicar correctamente el marxismo a la realidad de nuestro país. Por eso hay ahora dos organizaciones con tronco marxista. Las FPL consideró que la mejor aplicación del marxismo a las condiciones del país es la estrategia político-militar de la Guerra Popular Prolongada (...) Ustedes siguieron planteando la línea de las elecciones, de las vías pacíficas todavía durante varios años. Ahora se ha llegado más o menos a un consenso (...) gran parte de aquellas razones por las cuales hubo necesidad de que nos separásemos han menguado, aunque naturalmente no todas. ${ }^{29}$

La diferencia de este leninismo con el de Lenin es que este hacía el sectarismo a un lado en los períodos de auge en la lucha de masas; el leninismo de Marcial es inflexible y tiende a dividir la vanguardia en pleno ascenso de la guerra popular de liberación. La inflexibilidad se hace patente en el tema de la política de diálogo-negociación, vista por Marcial siempre con gran recelo y desconfianza. Su postura es maximalista:

Las FPL la negociación la concibe como un medio de lucha estratégico y auxiliar para permitir que nuestros combatientes puedan avanzar: ésa es la negociación. Y puede 
entrarse a una mesa de negociación, pero si se está bien claro de eso: en la defensa insobornable de los intereses del pueblo, se puede pasar peleando, ahí en la mesa de negociación meses y años, mientras avanzan nuestros ejércitos, mientras le dan el golpe de gracia a nuestro enemigo, genocida, y que aquella negociación se convierta precisamente en el triunfo, en firmar la rendición del enemigo; o condiciones de negociación que realmente sean ventajosas y favorables a los intereses de nuestro pueblo (...) ese ejemplo lo dio Vietnam, con la diferencia de que allí había un verdadero partido comunista único y que nadie actuaba de otra manera porque no había varias organizaciones con distintos enfoques... ${ }^{30}$

Entre El Salvador y Vietnam había otras diferencias esenciales que Marcial no percibe: allí la guerra de liberación nacional asumió la forma de guerra patriótica de todo el pueblo, pues la lucha era directamente contra un ejército imperialista invasor. Ho Chi Minh fue fundador del Partido Comunista, pero este dirigía un amplio abanico de organizaciones de diversa naturaleza y distintas clases sociales, pues la lucha fue primero contra los franceses, después los japoneses, otra vez los franceses y por último los norteamericanos. Fue el objetivo de la negociación la retirada del invasor, para posteriormente terminar de aplastar por la fuerza al Gobierno títere pro-colonialista. En segundo lugar, la estrategia empleada nunca fue "guerra popular prolongada", como Marcial equivocadamente creía. Los comandantes de las FPL y de las demás organizaciones del FMLN vinieron a darse cuenta de esto en sus estadías en Vietnam, de boca de los propios camaradas vietnamitas. Esos jefes militares regresaron con una concepción unificada de la estrategia del FMLN con el nombre de "guerra popular revolucionaria", sin las adherencias maoístas de la Guerra Popular Prolongada (GPP), que tan enfáticamente rechazaban los vietnamitas. Todo ello sobrepasó a Marcial, al que sus compañeros llamaban "el Ho Chi Minh de Centroamérica", pero que ahora resultaba descalificado justo en tierra vietnamita.

Sus intentos desesperados por recuperar el control de la dirección de las FPL, por frenar el proceso de unificación del FMLN y evitar el avance del diálogo-negociación, llevaron a Marcial al desencadenamiento de los fatídicos hechos de abril de 1983. No era primera vez en la historia que la izquierda incurría en crímenes políticos fratricidas: el caso de Trotsky, asesinado en México por órdenes de Stalin, o el todavía más próximo de Roque 
Dalton por la dirigencia del ERP, estaban muy vívidos en la memoria. Sin embargo, el impacto para la credibilidad del FMLN en conjunto fue muy grande, en especial en la escena internacional.

Pero, a la larga, ayudó a consolidar al FMLN como la única vanguardia, a rebajar el tono ideologizado, a aprender a manejar internamente las diferencias, a favorecer la coexistencia de corrientes de opinión en su seno. También para tener la audacia de abrirse a lo nuevo, incluido adentrarse en un terreno desconocido como era el del diálogo (desde 1984, por iniciativa de Duarte) y el de la negociación después (desde 1990, con el apoyo y presión de la comunidad internacional, en la figura de la Organización de las Naciones Unidas).

Ha sido toda una escuela política la que hubo que pasar en las sucesivas etapas del proceso, hasta desembocar en la salida políticonegociada tras doce largos años de contienda civil. Uno tiene la impresión de que si Marcial se hubiera impuesto en la pugna de 1983, ese proceso hubiera descarrilado: o la izquierda se hubiera descompuesto y liquidado en luchas intestinas, o bien en el país aún seguiríamos en guerra. Los mismos compañeros que proceden de las FPL parecieran confirmar esa impresión:

En algún momento del camino, creo que Marcial llegó a convertir aquello que inicialmente era una previsión objetiva, de la necesidad de una guerra de larga duración, a convertirlo en un valor en sí mismo. No era correcto (...). A fin de cuentas, la guerra no se prolongó porque existiese un concepto prolongado en los años setenta sino por la obstinación de nuestros oponentes. Fueron factores del proceso objetivo. Fue el precio que impusieron a este pueblo los malos militares, sus patrocinadores, su "miopía política" y su crueldad. Fue el precio para conseguir los primeros brotes de libertad que hoy vemos. ${ }^{31}$

Con referencia al leninismo, la visión de este dirigente revolucionario, conocido durante la guerra con el nombre de Valentín, ${ }^{32}$ es la siguiente: "La teoría leninista de partido fue muy útil en la lucha contra el régimen autoritario (...) pero ahora estamos en la posguerra, la situación tiende a ser otra y aquel esquema de partido no es el modelo que necesitamos". ${ }^{33}$ La revisión crítica del mencionado dirigente alcanza también al propio Marx: "El marxismo hoy en día es principalmente una valiosa herramienta de análisis, una vertiente de las ciencias sociales (...) la pretensión de convertir al marxismo en una 
cosmovisión y además, casi divina e infalible, es uno de los pecados fundamentales de los marxistas ortodoxos (...) de convertir esa teoría en una doctrina, más que en una ideología, yo diría, una teología". ${ }^{34}$
Una voz posiblemente más autorizada, en el sentido de que siempre se mantuvo alejada de cualquier pragmatismo o concesión ideológica, es la de Schafik Hándal, quien al respecto comentaba:

La verdad histórica es que no se aplicó el modelo de Lenin para la transición al socialismo, sino otro y fue este modelo el que llevó al socialismo a su crisis actual. Todo el sistema diseñado por él fue violado y eso condujo a todas las deformaciones verticalistas y autoritarias del Estado y del partido (...). Si bien se puede aceptar que hubo justificación temporal para un desarrollo autoritario, una vez que se logró el arranque inicial la estrategia debió ser corregida y reajustada para dar cabida a la democracia, esencial para cristalizar la sociedad socialista. Los fundadores del marxismo siempre consideraron la democracia como un atributo inseparable del socialismo; la dictadura del proletariado es un concepto teórico para dar cuenta de una democracia práctica mucho más profunda y extensa que la democracia limitada de todo régimen burgués, aun del más representativo, que es siempre una democracia al servicio de una minoría. ${ }^{35}$

La sinceridad y solidez de los planteamientos de este líder histórico salvadoreño quedan de relieve si tomamos en cuenta el momento en que fueron hechos: 1990. Es decir, cuando todavía existía la Unión Soviética, aunque era muy evidente la profunda crisis en que se había sumergido. Como destaca Marta Harnecker, citando a Schafik, en la introducción: "El socialismo no se puede renovar sin defenderse, ni se puede defender sin renovarse" ${ }^{\prime 36}$ Tal postura, aunque pareciera una defensa de la Perestroika que venía impulsando Gorbachov, a la vez puede entenderse como un reclamo por la indefensión en que dejó al socialismo; por otro lado, podría interpretarse como una justificación de la posición cubana, muy escéptica y crítica respecto de la Perestroika, pero también constituye un recordatorio de la impostergable necesidad de renovación.

Respecto a la visión estratégica de la izquierda y lo que se necesita en El Salvador, las ideas de Schafik son iluminadoras: 
Hace ya mucho tiempo que para nosotros está claro que la revolución socialista, especialmente en países atrasados, tiene un prólogo en la revolución democrática, la cual configura, de acuerdo a las condiciones nacionales e internacionales de cada revolución, un proceso de transición al socialismo que, en algunos casos, puede ser muy largo (...). En realidad se trata de una sola y misma revolución, cuyas tareas generan un proceso continuo de cambios y desarrollo que asegura la construcción del socialismo, a partir de los profundos cambios estructurales políticos, económicos y sociales que realiza la revolución democrática. ${ }^{37}$

Finalmente, con respecto al papel de la empresa privada, la postura del viejo líder comunista es clara:

En nuestro proyecto objetivamente hay espacio para la empresa privada. (...) El carácter nacional del proyecto es un factor capaz de ganar el interés y la participación de estos sectores (...). Repito, el patriotismo, la posibilidad de un desarrollo integral del país, la activa participación del pueblo, su florecimiento cultural, la democracia, son estímulos capaces de decidir el rumbo de la conducta individual, incluso en señores del capital. ${ }^{38}$

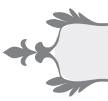

Las condiciones de la lucha política en El Salvador de posguerra, tras la intensa etapa del conflicto armado, ya superadas la persecución y clandestinidad propias de la dictadura, son más proclives a la utilización de las categorías de Gramsci y menos a las del leninismo. Gramsci enfatiza la importancia de lo ideológico-superestructural, relativizando mucho el carácter determinante de lo económico. Incluso su valoración -positiva- de la revolución bolchevique la hace destacando los rasgos de voluntarismo, a despecho de lo

\section{Gramsci en El Salvador}

que parecieran dictar los hechos económicos.

En su famoso texto "La revolución contra El Capital", este marxista italiano señala: "La revolución de los bolcheviques (...) es la revolución contra El Capital de Carlos Marx. El Capital, de Marx, era en Rusia el libro de los burgueses más que de los proletarios. Era la demostración crítica de la fatal necesidad de que en Rusia se formara una burguesía, empezara una era capitalista, se instaurase una civilización de tipo occidental, antes de que el 
proletariado pudiese pensar siquiera en su ofensiva, en sus reivindicaciones de clase, en su revolución" ${ }^{\prime 3}$ $Y$ concluye Gramsci: "Los hechos han superado las ideologías".

Más adelante profundiza en la manera especial en que, a su entender, los bolcheviques "no son marxistas", pues reniegan de algunas afirmaciones de $E I$ capital, pero no reniegan, por el contrario, "viven el pensamiento marxista, el que nunca muere (...) [que] no sitúa nunca como factor máximo de la historia los hechos económicos en bruto sino siempre el hombre, la sociedad de los hombres, de los hombres que se reúnen, se comprenden, desarrollan a través de esos contactos (cultura) una voluntad social, colectiva, y entienden los hechos económicos, los juzgan, los adaptan a su voluntad hasta que esta se convierte en motor de la economía, en plasmadora de la realidad objetiva, la cual vive entonces, se mueve y toma el carácter de materia telúrica en ebullición, canalizable por donde la voluntad lo desee, y como la voluntad lo desee" $^{\prime 4}{ }^{40}$

Así como valora al leninismo, valora asimismo al marxismo. Se pregunta, en un modo para nada ortodoxo: "¿Somos marxistas? ¿Existen marxistas? Tú sola, estupidez, eres eterna". Y tras estas palabras iniciales, que pueden haber dejado perplejo a más de alguno, prosigue su exposición de cómo ve al marxismo y a su fundador: "Marx no ha escrito un credillo, no es un mesías (...) no es solo un científico, sino también un hombre de acción; es grande y fecundo en la acción igual que en el pensamiento, y sus libros han transformado el mundo así como han transformado el pensamiento" ${ }^{41}$

La definición gramsciana de 'crisis' caracteriza cabalmente nuestra guerra civil: "Consiste en que muere lo viejo, sin que pueda nacer lo nuevo". En El Salvador caía la dictadura, al darse el golpe de Estado del 15 de octubre de 1979, pero no nacía la democracia sino con el Acuerdo de Paz, el 16 de enero de 1992. Es un tiempo sin la una ni la otra, tiempo de crisis.

La crisis, para Gramsci, se da cuando "la clase dominante ha perdido el consentimiento, o sea, ya no es 'dirigente' sino solo 'dominante', detentadora de la mera fuerza coercitiva, ello significa que las grandes masas se han desprendido de las ideologías tradicionales, no creen ya en lo que antes creían, etc". ${ }^{42}$ Pareciera una prolongación de las reflexiones de Juan Jacobo Rousseau, el ideólogo de la lucha por la independencia de las siete colonias, de la que nacería Estados Unidos, así como de la Revolución francesa. Decía el ginebrino: "Si es la fuerza la que hace al derecho, ¿qué derecho es ése que perece cuando la fuerza cesa?; si es preciso 
obedecer por la fuerza, entonces no es necesario obedecer por deber; la fuerza no constituye derecho, no se está obligado a obedecer sino a los poderes legítimos". ${ }^{43}$

Gramsci caracteriza la "crisis orgánica". Esta consiste en "crisis de hegemonía de la clase dirigente", que se traduce en una "crisis de autoridad", que deriva en una "crisis del Estado en su conjunto". La describe así: "Al Ilegar a un cierto punto de su vida histórica los grupos sociales se separan de sus partidos tradicionales; es decir, los partidos tradicionales dejan de ser reconocidos como expresión propia por su clase o su fracción de clase" ${ }^{44}$ $Y$ sigue una advertencia que en su contexto probablemente iba referida al fascismo y a Mussolini, que en El Salvador bien podríamos aplicar al Partido Demócrata Cristiano (PDC) instrumentalizado por Reagan o a ARENA, al mesiánico Napoleón Duarte o al escuadronero Roberto d’Aubuisson. Advertía Gramsci lo siguiente: "Cuando se producen estas crisis, la situación inmediata se hace delicada y peligrosa, porque queda abierta a las soluciones de fuerza, a la actividad de potencias oscuras, representadas por hombres providenciales o carismáticos" ${ }^{45}$

En condiciones normales se evitan los riesgos de desestabilización mediante un recurso de naturaleza ideológica. "Es la ascendencia cultural de la clase dominante la que garantiza esencialmente la esta- bilidad del orden capitalista" ${ }^{46}$ Por ello mismo puede resumirse que, en esencia, la hegemonía "significa subordinación ideológica". ${ }^{47} \mathrm{La}$ 'filosofía de la praxis' (es decir, el marxismo) tiene que esforzarse en generar una nueva hegemonía, socialista, y para ello deberá "crear un nuevo sentido común". Ello pasa por generar "una voluntad colectiva revolucionaria" y para llegar a la cual habrá que emprender "la crítica del sentido común". Es decir, lograr que ciertas ideas de que son portadoras las fuerzas del socialismo se impongan en la sociedad con la fuerza lógica de las cosas que "caen por su propio peso". En eso consiste la conquista del sentido común, que no es más que la filosofía simplificada al nivel de la comprensión de las amplias masas.

La revolución será, entonces, la consecuencia de haber logrado cambiar la cosmovisión de las masas. "La revolución es la conquista de las masas para una nueva voluntad práctica; es el producto de la irrupción de la conciencia y la voluntad en la historia". ${ }^{48}$ Implica nuevos valores y nueva cultura; implica la reforma intelectual y moral.

Esta concepción gramsciana se desprende de su conceptualización del poder en sociedades capitalistas de mayor complejidad. "El poder no se encuentra solo en el Estado, sino que está difundido en muchos centros de la sociedad". De ahí 
que pueda ofrecer un listado de los 'aparatos de hegemonía' por cuyo medio se ejerce la función hegemónica: medios de comunicación, iglesias, instituciones educativas, centros de cultura, etc. ${ }^{49}$ Funcionan como otras tantas trincheras en la llamada 'guerra de posiciones'.

Gramsci realiza una fecunda analogía entre la guerra y el ejercicio de la política. Hay dos formas de guerra, de movimiento y de posiciones, o planteado de otra manera, guerra de maniobra y guerra de asedio. Pues bien, en la política, en la lucha revolucionaria ha de estar claro si se está en el primer o en el segundo esquema. El primero supone la lucha frontal, el asalto a la fortaleza enemiga. Fuera el caso de la Revolución rusa, pero también de la huelga general o de los movimientos insurreccionales. Es válido frente a dictaduras. En cambio, el segundo escenario implica un enfrentamiento largo y paciente, la ocupación de trincheras, fortificaciones y casamatas, el desgaste del sistema organizativo e industrial del territorio de la retaguardia. Donde hay una robusta estructura de la sociedad civil es imprescindible adoptar la estrategia de la 'guerra de posiciones', pues en tales casos la pugna no se reduce al control del Estado, pues este es solo "una trinchera de avanzada" ${ }^{50}$

Para alcanzar el triunfo en una confrontación de tales características se requiere proceder como Maquia- velo recomendaba en su obra $E I$ Príncipe. Su autor trataba de dotar a Italia de una monarquía absoluta como la que tenían potencias como Alemania, España o Francia, que asolaban la península itálica con sus poderosos ejércitos. Gramsci lo interpreta como el "fracaso sucesivo en crear una voluntad colectiva nacional-popular". ${ }^{51}$ Con otras palabras, el uso deficiente de los instrumentos de hegemonía dio como resultado la debilidad de la clase dominante frente a los grupos subalternos y frente a poderes externos. "La burguesía italiana no supo unificar alrededor suyo al pueblo y esta fue la causa de sus derrotas y de la interrupción de su desarrollo" ${ }^{\prime 52}$

En nuestra época, a diferencia del príncipe de Maquiavelo, "el príncipe moderno no puede ser una persona real, el mito-príncipe, un individuo concreto; solo puede ser un organismo (...) creado ya por el desarrollo histórico: es el partido político". Y Gramsci lo describe así: "La primera célula en la que se reúnen unos gérmenes de voluntad colectiva que tienden a convertirse en universales y totales". ${ }^{53} \mathrm{La}$ función del partido es básicamente intelectual y es complementaria de la labor que realizan los intelectuales individuales. Los que elaboran ideológicamente los intereses de la clase dominante son 'intelectuales orgánicos'. También los grupos subordinados deben dotarse de sus propios 'intelectuales orgánicos' individuales y 
colectivos, es decir, personalidades que elaboran la filosofía y el sentido común nuevo, al servicio de las masas populares, y el partido político que las conduce en la compleja lucha de la guerra de posiciones, a la conquista de la hegemonía, desplazando a la burguesía.

Gramsci puntualiza: "El protagonista del nuevo Príncipe no puede ser en la época moderna un héroe personal $^{54}$ sino que debe ser el partido político". Pero distingue unos de otros. Así, explica: "Los partidos orgánicos y fundamentales, por razones de la lucha o por otra causa, se han dividido en fracciones, cada una de las cuales toma el nombre de partido e incluso de partido independiente. Por esto, el Estado Mayor intelectual del partido orgánico a menudo no pertenece a ninguna de estas fracciones sino que opera como si fuese una fuerza dirigente que se sostiene por sí misma, superior a los partidos y a veces considerada como tal por el público" ${ }^{.5}$

Gramsci formula un interro-

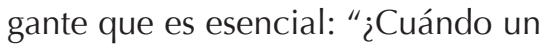
partido se hace necesario históricamente?" Y ofrece dos respuestas que son complementarias: "Cuando se genera la convicción de que es necesaria determinada solución de los problemas vitales"; "cuando las condiciones de su triunfo, de su indefectible conversión en Estado, están al menos en vías de formación". Para que un partido pueda pervivir, en condiciones normales, deben confluir tres elementos fundamentales: primero, "un elemento difuso, de hombres comunes, medios, cuya participación está posibilitada por la disciplina y la fidelidad"; segundo, se necesita el que los centralice, organice y discipline, los "capitanes" ("se habla de capitanes sin ejército -dice Gramsci-, pero en realidad es más fácil formar un ejército que formar capitanes"); y tercero, "el elemento que articule el primero con el segundo", "que los ponga en contacto intelectual y moral", y este elemento es: "La convicción férrea de que es necesaria una determinada solución de los problemas vitales". ${ }^{56}$ Este último actúa como un fermento.

Es una concepción de partido que tiene ciertos puntos en común con la idea leninista, pero también grandes contrastes. Sin coincidir en el concepto de partido de cuadros, sin embargo la importancia que Gramsci presta a "los capitanes" guarda cierto paralelismo. Si el partido perdiera sus bases, por la represión u otro motivo, podría reconstruirse a partir del segundo elemento. Así como Lenin ha considerado al "cuadro" como aquel militante revolucionario que él solo es ya el partido, que en caso de quedar aislado fuera capaz, como una célula en la metáfora biológica, de reproducirse, lograr crecer y hacer nacer de nuevo al partido. 
Por otro lado, el "fermento" de que habla Gramsci -la "levadura" en la metáfora cristiana- es el tercer elemento, el "cemento" ideológico que une al partido, desde la base hasta las estructuras de dirección, que hace crecer "la masa" en la imagen bíblica del pan de trigo, que fermenta la leche hasta producir el yogur en la metáfora turco-griega. Gramsci pone lo ideológico en el centro de la existencia del partido y de su relación con las masas.

\section{Referencias bibliográficas}

os Bujarin, N.: (1978) Lenin marxista, Barcelona, España, Fontamara.

os Carpio, S. C.: (1999) Nuestras montañas son las masas, Viena, Austria, Der Keil.

os Díaz-Salazar, R.: (1993) Gramsci y la construcción del socialismo, San Salvador, UCA/Editores.

os Díez del Corral, F.: (2003) Lenin, una biografía, Barcelona, España, Folio.

os Ellacuría, I.: (1981) "El objeto de la filosofía", en Ellacuría, I.: (1990) Filosofía de la realidad histórica, San Salvador, El Salvador, UCA/Editores.

os Fernández Buey, F.: (2001) Leyendo a Gramsci, Barcelona, España, El Viejo Topo.

os Fernández Lira/Alegre Zahonero: (2011) El orden de El Capital, Caracas, Venezuela, El perro y la rana.

os Gramsci, A.: (1971) La política y el Estado moderno, Barcelona, España, Península.

os Gramsci, A.: (1987) Antología, (La revolución contra El Capital), México, siglo XXI.

os Hándal, S. J.: (1991) El socialismo: ¿una alternativa para América Latina? Schafik Jorge Hándal entrevistado por Marta Harnecker, San Salvador, Alternativa. 
os Hart, A.: (2005) Marx, Engels y la condición humana, La Habana, Cuba, Ocean Sur.

os Lefébvre, H.: (1976) Hegel, Marx, Nietzsche, México, siglo XXI.

os Lenin, V. I.: (1951) ¿Qué hacer? Problemas candentes de nuestro movimiento, Moscú, Rusia, Progreso.

os Lenin, V. I.: (1974) El desarrollo del capitalismo en Rusia, Barcelona, España, Ariel.

os Lenin, V. I.: (1974) Imperialismo, fase superior del capitalismo, México, Roca.

os Macciocchi, M. A.: (1975) Gramsci y la revolución de occidente, México, Siglo XXI.

os Mandel, E.: (1971) La teoría leninista de la organización, México, ERA.

os Marx, K.: (1979) Prólogo a Contribución a la crítica de la economía política, México, Cultura Popular.

os Mészáros, I.: (1978) La teoría de la enajenación en Marx, México, ERA.

os Palloix, C.: (1977) La cuestión del imperialismo en Lenin y Rosa Luxemburgo, Madrid, España, Castellote.

os Ribera, R.: (2012) Ensayos de filosofía política y social [Para leer a Rousseau] [Para leer a Marx] San Salvador, El Salvador, Cuadernos de cátedra (66), UCA.

os Sacristán, M.: (1983) "¿Qué Marx se leerá en el siglo XXI?", Mientras tanto (16-17), agosto-noviembre., Barcelona, España.

os Stalin, J.: (1970) Los fundamentos del leninismo, México, Grijalbo.

os Ueltzen, S.: (1994) La fuerza emancipadora: de la primera a la segunda utopía. Entrevista con Gerson Martínez, San Salvador, El Salvador, Algier's.

os VV. AA.: (1976) Revolución y democracia en Gramsci, Barcelona, España, Fontamara.

os Zinoviev, G.: (1975) El leninismo, texto incluido en el tomo II de la obra VV. AA.: El gran debate (1924-1926), México, siglo XXI.

os Zizek, S.: (2004) A propósito de Lenin, Buenos Aires, Argentina, Atuel/ Parusía. 


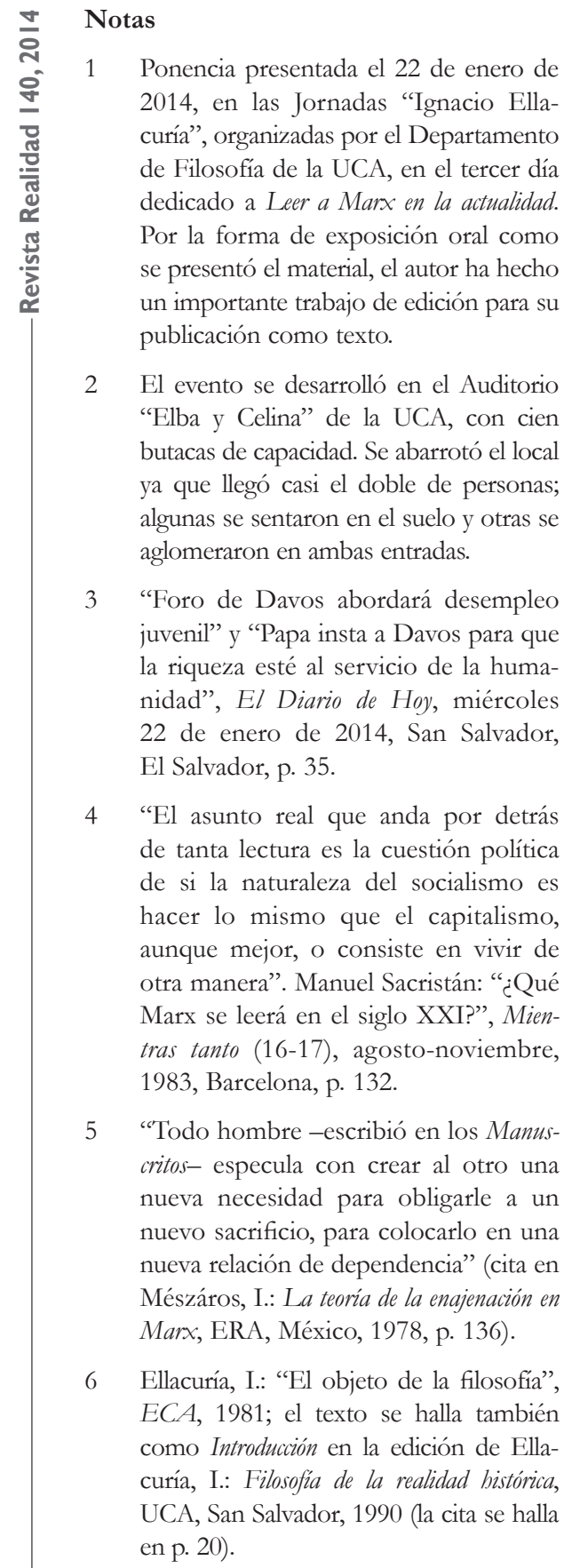

7 "En Hegel se puede encontrar casi todo lo que dijo Marx" (Lefébvre, H.: Hegel, Marx, Nietzsche, siglo XXI, México, 1976, p. 13).

8 "La historia de la humanidad hasta nuestros días es la historia de la lucha de clases": es la primera frase del Manifiesto del Partido Comunista y piedra angular del materialismo histórico.

9 La citas son hechas por Zinoviev, G.: El leninismo, texto incluido en el tomo II de la obra VV.AA.: El gran debate (1924-1926), siglo XXI, México, 1975, pp. 12 y 13.

10 Prefacio a la primera edición, Lenin, V. I.: El desarrollo del capitalismo en Rusia, Ariel, Barcelona, 1974, p. 18.

11 Ibidem, Prefacio a la segunda edición, p. 12.

12 Zizek, S.: A propósito de Lenin, Atuel/ Parusía, Buenos Aires, 2004, p. 14.

13 Ibidem, pp. 15 y 16.

14 Stalin, J.: Los fundamentos del leninismo, Grijalbo, México, 1970, p. 56.

15 Zizek, S.: idem, p. 46.

16 Sacristán, M.: "Sobre el estalinismo", Mientras tanto (40), primavera de 1990, Barcelona.

17 Bujarin, N.: Lenin marxista, Fontamara, Barcelona, 1978.

18 Stalin, J.: opus cit., p. 21.

19 Lenin: Imperialismo, fase superior del capitalismo, citado por Palloix, C.: La cuestión del imperialismo en Lenin y Rosa Luxemburgo, Castellote, Madrid, 1977, p. 54.

20 Lenin: Imperialismo, fase superior del capitalismo", Roca, México, 1974, pp. 115 y 116. 
21 Es el nombre que en la época llevaban las organizaciones marxistas, fueran reformistas o revolucionarias.

22 Lenin, V. I.: ¿Qué hacer?, Progreso, Moscú, 1951, p. 145.

23 Marx, K.: Prólogo a Contribución a la crítica de la economía política, Cultura Popular, México, 1979, p. 12.

24 Díez del Corral, F.: Lenin, una biografía, (el Viejo Topo, 1999) Folio, Barcelona, 2003, p. 126.

25 Ibidem, p. 130.

26 Lenin, V. I.: opus cit., p. 147.

27 Citado por Bujarin, N.: opus cit., p. 31.

28 Carpio, S. C.: Nuestras montañas son las masas, Der Keil, Viena, 1999, pp. 49 y 50.

29 Ibid., p. 92.

30 Carpio, S. C.: Testamento politico, en opus cit., p. 162.

31 Ueltzen, S.: La fuerza emancipadora: de la primera a la segunda utopía. Entrevista con Gerson Martinez, Algier's, San Salvador, 1994, pp. 21 y 22

32 Gerson Martínez fue el director general del programa de gobierno propuesto por Mauricio Funes cuando fue candidato a la presidencia en 2009 y vuelve a serlo en la campaña presidencial del FMLN de 2014.

33 Ibidem, p. 34.

34 Ibidem, pp. 31 y 32.

35 Hándal, S. J.: El socialismo: ¿una alternativa para América Latina? Schafik Jorge Hándal entrevistado por Marta Harnecker, Alternativa, San Salvador, 1991, pp. 26 y 27.

36 Ibidem, p. 12.

37 Ibid., p. 43.

38 Ibid., p. 53.
39 Gramsci, A.: "La revolución contra El Capital", en Antología, siglo XXI, México, 1987, p. 34.

40 Ibidem, p. 35

41 Gramsci, A.: "Nuestro Mar", opus cit., p. 38 .

42 Gramsci, A.: "Oleada de materialismo y crisis de autoridad", opus cit., p. 313.

43 Rousseau, J. J.: El contrato social, citado en Ribera, R.: Ensayos de filosofía política y social [Para leer a Rousseau], Cuadernos de cátedra (66), UCA, San Salvador, 2012, p. 58 .

44 Gramsci, A.: La política y el Estado moderno, Península, Barcelona, 1971, p. 117.

45 Ibidem.

46 Díaz-Salazar, R.: Gramsci y la construcción del socialismo, UCA, San Salvador, 1993, p. 228 .

47 Ibidem.

48 Idem, pp. 225 y 231.

49 Idem, p. 243.

50 Gramsci, A.: "La política y el Estado moderno", opus cit., p. 136.

51 Ibid., p. 68.

52 Gramsci, A.: "Apuntes sobre la historia de las clases subalternas", opus cit., p. 493.

53 Gramsci, A.: (Notas sobre la política de Maquiavelo) La política y el Estado moderno, opus cit., p. 67.

54 Discutible, tanto en el siglo XX como en el nuestro. Gramsci no conoció los casos de Mao, Kim il Sung, Fidel Castro y, en nuestra centuria actual, el "fenómeno" Hugo Chávez.

55 Gramsci, A.: La política y el Estado moderno, opus cit., pp. 83 y 84.

56 Gramsci, A.: Antología, opus cit., p. 348. 